\title{
Local Immune Regulation of Mucosal Inflammation by Tacrolimus
}

\author{
Jolanda M. van Dieren • Margaretha E. H. Lambers • Ernst J. Kuipers • \\ Janneke N. Samsom $\cdot$ C. Janneke van der Woude $\cdot$ Edward E. S. Nieuwenhuis
}

Received: 26 February 2009/ Accepted: 27 October 2009/Published online: 1 December 2009

(c) The Author(s) 2009. This article is published with open access at Springerlink.com

\begin{abstract}
Purpose Tacrolimus is a potent immunomodulator that is effective in the treatment of inflammatory bowel disease (IBD). However, potential toxicity and systemic effects with oral intake limit its use. Local tacrolimus treatment is effective in a subgroup of proctitis patients. This study aimed to evaluate whether colonic mucosal immune cells are susceptible to locally applied tacrolimus in vitro. Our in vivo studies aimed at evaluating whether local tacrolimus treatment in mice would bring about local immune suppression and to compare colonic and systemic tacrolimus levels after locally and systemically applied tacrolimus.

Results In vitro tacrolimus inhibited the activation of multiple cell types present in colonic tissue; lamina propria $\mathrm{T}$ cells, NKT cells, and both classical- and non- classical antigen presenting cells. However, the cytokine production of epithelial cells was not inhibited by tacrolimus at these concentrations. After rectal administration in mice, tacrolimus blood levels were comparable to those obtained by oral intake. However, rectally treated mice exhibited a 14-fold higher concentration of tacrolimus within their colonic tissue than orally treated mice. Moreover, rectally
\end{abstract}

J. M. van Dieren $(\square)$ · E. J. Kuipers · C. J. van der Woude Department of Gastroenterology and Hepatology, Erasmus MC, University Medical Center, 's Gravendijkwal 230, 3015 CE

Rotterdam, The Netherlands

e-mail: j.vandieren@erasmusmc.nl

J. M. van Dieren · M. E. H. Lambers · J. N. Samsom

E. E. S. Nieuwenhuis

Laboratory of Pediatrics, Division of Gastroenterology and

Nutrition, Erasmus MC, University Medical Center,

Dr. Molewaterplein 50, 3015 GE Rotterdam,

The Netherlands applied tacrolimus resulted in a local but not a systemic immune suppression in mice.

Conclusions Tacrolimus inhibits activation of several pivotal immune cells of the intestinal mucosa. Murine studies indicate that colonic application of tacrolimus induces local rather than systemic immune suppression.

Keywords Colonic mucosa - Tacrolimus .

Local immune suppression .

Inflammatory bowel disease (IBD)

\section{Introduction}

Calcineurin inhibitors, such as tacrolimus and cyclosporine, are a subset of immunomodulators that potently inhibit lymphocyte proliferation and activation [1]. They are best known for their immunosuppressive capacities in prevention of allograft rejection. In addition, systemic treatment with calcineurin inhibitors has been shown to be effective in the treatment of IBD. However, general systemic immune suppression, potential side-effects (insulin resistance, hypertension, neurological disorders) and potential toxicity (hepatotoxitcity and nephrotoxicity) limit the use of calcineurin inhibitors.

Local treatment of colitis patients by means of enemas or suppositories of various drugs is associated with local efficacy and less systemic side-effects. As such, prednisone and 5-ASA enemas and suppositories are widely prescribed for IBD patients with distal colitis or proctitis. Unfortunately, there is a subset of patients unresponsive to these local treatments, making systemic treatment, with all its side-effects, inevitable. Therefore, there is a need for the development of new local treatments for patients with distal colitis or proctitis. 
Tacrolimus, formally known as FK506, is one of the calcineurin inhibitors found to be effective for the systemic treatment of ulcerative colitis [2-6]. We [7] and others [8] recently described the therapeutic effect of local tacrolimus treatment in patients with therapy-resistant distal colitis in two pilot studies.

The aim of this study was to validate local application of tacrolimus in IBD by studying the immunomodulatory effect of this drug on several classes of immune cells that are implicated in the aberrant mucosal immune responses associated with IBD, e.g., epithelial cells, antigen presenting cells, and lamina propria $\mathrm{T}$ cells. A subset of $\mathrm{T}$ cells, namely the CD1d-restricted NKT cells, have also been implicated in IBD pathogenesis [9]. Therefore, we also studied the effect of tacrolimus on this specific subset of T cells. Furthermore we assessed the levels of tacrolimus within colonic tissue and the extent of local immune suppression after rectal administration in mice.

\section{Methods}

\section{In Vitro Studies}

\section{Treatment of Epithelial Cells with Tacrolimus}

A colonic epithelial cell line (Caco-2) was pre-incubated for $6 \mathrm{~h}$ with a range of tacrolimus (Prograf, Fujisawa) concentrations, from 0 to $100,000 \mathrm{ng} / \mathrm{ml}$, washed three times, and subsequently stimulated with $30 \mu \mathrm{g} / \mathrm{ml}$ peptidoglycan (from bacillus subtilis, Fluka/Sigma-Aldrich). After $24 \mathrm{~h}$ of incubation with tacrolimus, IL-8 production was measured in the supernatant by means of enzymelinked immunosorbent assay (ELISA, OptEIA mouse IL-8 ELISA set, BD Biosciences Pharmingen).

\section{Treatment of (NK)-T Cells with Tacrolimus}

Colonic lamina propria mononuclear cells were isolated from naïve $\mathrm{BALB} / \mathrm{C}$ mice as described earlier [10] and were stimulated ex vivo with $2 \mu \mathrm{g} / \mathrm{ml} \alpha \mathrm{CD} 3$ (BD Biosciences, clone 145-2C11) and $2 \mu \mathrm{g} / \mathrm{ml} \alpha \mathrm{CD} 28$ (BD Biosciences, clone 37.51) antibodies in the presence of a range of tacrolimus concentrations. After $72 \mathrm{~h}$ supernatant was collected and IL-2 concentrations were measured by means of ELISA (OptEIA, human IL-2 ELISA set, BD Biosciences Pharmingen).

A CD1d-restricted NKT cell line (DN32.D3), kindly provided by Richard Blumberg, was pre-treated with a range of tacrolimus concentrations, from 0 to $1,000 \mathrm{ng} / \mathrm{ml}$, for $24 \mathrm{~h}$. Subsequently, NKT cells were stimulated with $5 \mathrm{ng} / \mathrm{ml}$ phorbol ester 12-tetradecanoylphorbol-13 acetate (PMA, Sigma-Aldrich) and $100 \mathrm{ng} / \mathrm{ml}$ calcium ionofore
(Sigma-Aldrich). After $24 \mathrm{~h}$ of stimulation, IL-2 concentrations were measured in the supernatant by means of ELISA.

\section{Treatment of Antigen Presenting Cells with Tacrolimus}

Dendritic cells were cultured from BALB/C bone marrow as previously described [11]. Thereafter, the protein ovalbumin (OVA) (calbiochem, EMD biosciences) was added at a concentration of $1 \mathrm{mg} / \mathrm{ml}$ and incubated in the presence of a range of tacrolimus concentrations. After $6 \mathrm{~h}$, the DCs were

Fig. 1 Tacrolimus inhibits the activity of mucosal T cells and antigenpresenting cells but leaves epithelial cells unaffected in vitro. Asterisks indicate statistical significance $(P<0.05)$, bars represent the mean of at least four wells per condition. Error bars indicate the standard error of the mean. The data shown are representative for at least two independent experiments. a Caco- 2 cells were pre-incubated for $6 \mathrm{~h}$ with increasing amounts of tacrolimus and subsequently stimulated with peptidoglycan for $24 \mathrm{~h}$. Bars indicate the average IL-8 production. The grey bar indicates the basal release of IL-8 of unstimulated Caco- 2 cells. White bars indicate IL- 8 production of peptidoglycan stimulated Caco-2 cells, incubated with increasing amounts of tacrolimus. Tacrolimus did not result in a significant inhibition of IL-8 production by epithelial cells. b Lamina propria lymphocytes (LPL) were isolated from murine colon and stimulated ex vivo for $72 \mathrm{~h}$ with $\alpha \mathrm{CD} 3 / \alpha \mathrm{CD} 28$ antibodies in the presence of increasing amounts of tacrolimus. IL-2 was measured in the supernatant by means of ELISA. Bars indicate the average IL-2 production. Significant inhibition of IL-2 production was observed at a tacrolimus dose of $1 \mathrm{ng} / \mathrm{ml}$. c NKT cells derived from the cell line DN32.D3 were pre-treated for $24 \mathrm{~h}$ with a range of tacrolimus concentrations and subsequently stimulated with PMA/calcium-ionophore for another $24 \mathrm{~h}$. IL-2 was measured in the supernatant by means of ELISA. Bars indicate the average IL-2 production of NKT cells. A dose-dependent inhibition of IL-2 production by tacrolimus is observed. $\mathbf{d}-\mathbf{f}$ Dendritic cells were loaded with the protein antigen OVA in the presence of increasing amounts of tacrolimus and washed three times after $6 \mathrm{~h}$ of incubation. Subsequently, DCs were co-cultured for $72 \mathrm{~h}$ with CFSElabeled $\mathrm{T}$ cells, which have a transgenic OVA-specific $\mathrm{T}$ cell receptor (DO11-10 T cells). d Proliferation of T cells was analyzed by FACS analysis of CFSE-positive cells. CD4 positivity is shown on the $\mathrm{Y}$-axis. CFSE positivity is shown on the X-axis. As CFSE is equally divided over daughter cells in a cell division, decreasing levels of CFSE indicate the number of divisions the cells have undergone. A high number of cells remain in an undivided state when DCs were incubated with tacrolimus. e Percentages shown in this graph are derived from the FACS data shown above (Fig. 1d). Bars indicate the percentage of cells within a specific round of division. Tacrolimus inhibits the capacity of DCs to induce division of T cells as there is a shift towards a higher percentage of undivided $\mathrm{T}$ cells and $\mathrm{T}$ cells that are in their first division and a lower percentage of cells that are in their third or fourth divisions. f IFN- $\gamma$ production was measured in the supernatant after $72 \mathrm{~h}$ by means of ELISA. Bars indicate the average IFN- $\gamma$ production of $\mathrm{T}$ cells. A dose-dependent decrease of IFN- $\gamma$ production is observed. $\mathbf{g}$ The Cd1d transfected epithelial cell line T84d was loaded with the lipid antigen $\alpha$ GalCer in the presence of increasing amounts of tacrolimus and washed three times after $18 \mathrm{~h}$ of incubation. Subsequently, T84d cells were co-cultured for $24 \mathrm{~h}$ with DN32.D3 cells, which have a $\alpha$ GalCer responsive T cell-receptor. IL-2 was measured in the supernatant by means of ELISA. Bars indicate the average IL-2 production by DN32.D3 cells. A dose-dependent decrease of IL-2 production is observed 
harvested, washed three times with medium, and the viable DCs were counted and plated in a 96-well culture plate. Meanwhile, $\mathrm{T}$ cells with an OVA specific T cell receptor were isolated from DO-11-10 mice and labeled with $5 \mu \mathrm{M}$ CFSE (Molecular Probes). DCs and T cells were co-cultured at a ratio of 1:10 and harvested after $72 \mathrm{~h}$. Proliferation of lymphocytes was determined by flow cytometric analysis (FACStar, BD Biosciences). Thereto, cells were stained with $\mathrm{CD} 4$ and $\mathrm{Kj}$ (which is the marker for the OVA specific $\mathrm{T}$ cell receptor) antibodies (CD4-PE, clone L3T4- GK1.5, BD Biosciences Pharmingen and KJ1-26 anti-TCR-biotin, Caltag, Burlingame, CA, respectively). After FACS measurement, CFSE peaks were analyzed within a CD4/Kj double positive gate. Culture supernatants were analyzed after $72 \mathrm{~h}$ for IFN- $\gamma$ production by means of ELISA (using anti-mouse INF- $\gamma$, clone XMG 1.2, Biolegend).

The epithelial cell line T84d, kindly provided by Richard Blumberg, which is an epithelial cell line transfected with the non-classical antigen-presenting molecule CD1d [12, 13], was loaded with $100 \mathrm{ng} / \mathrm{ml}$ of the NKT cellspecific lipid antigen $\alpha$-galactosylceramide ( $\alpha \mathrm{GalCer}$, Alexis Biochemicals) in the presence of a range of tacrolimus concentrations. After $18 \mathrm{~h}$ of incubation, the epithelial cells were washed three times with medium and subsequently co-cultured at a ratio of $1: 1$ with NKT cells (of the cell line DN32.D3), which have a $\alpha$ GalCer responsive T cell receptor. After $24 \mathrm{~h}$, the supernatant was collected and IL-2 production was determined by means of ELISA.

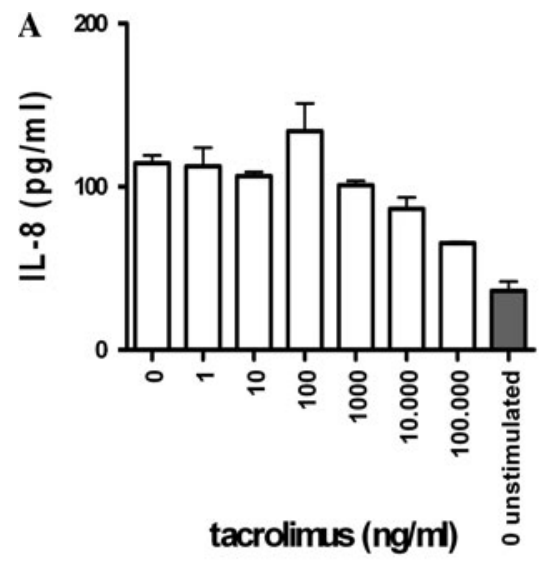

D

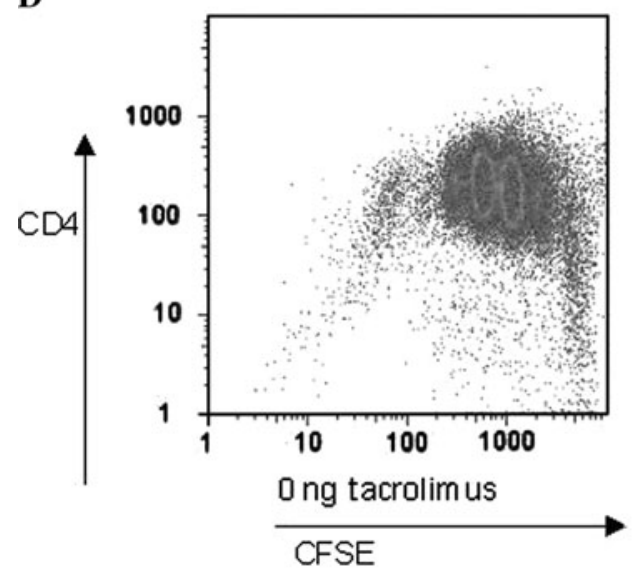

$\mathbf{E}$
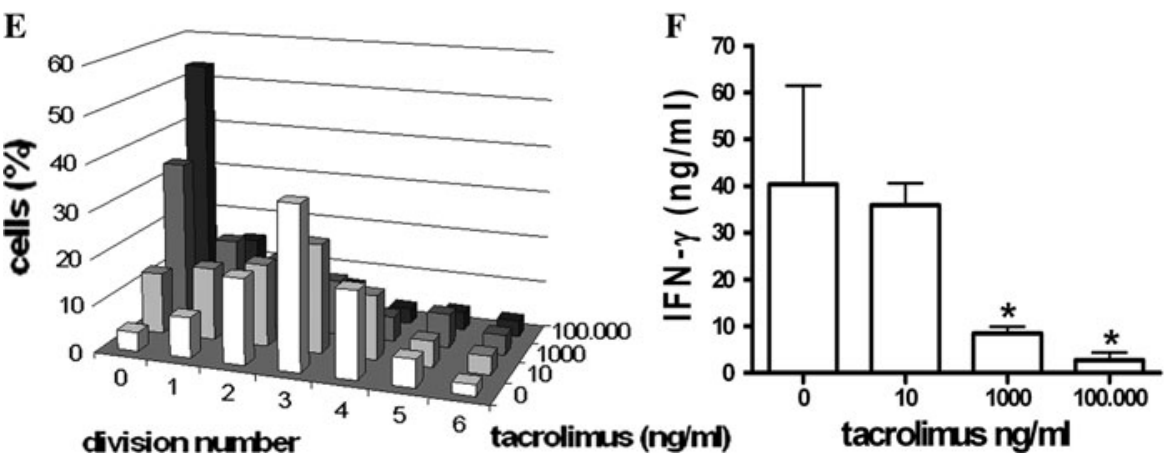

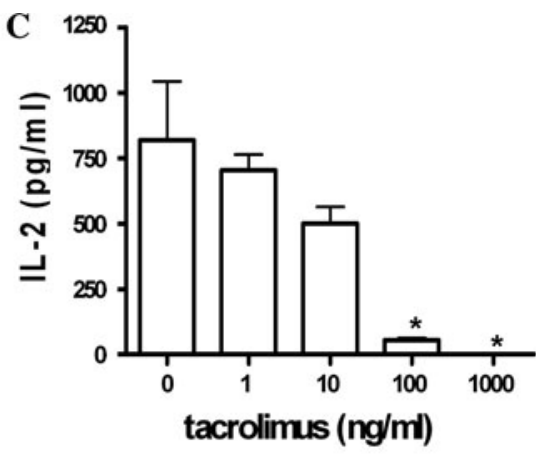

tacrolimus (ng/ml)
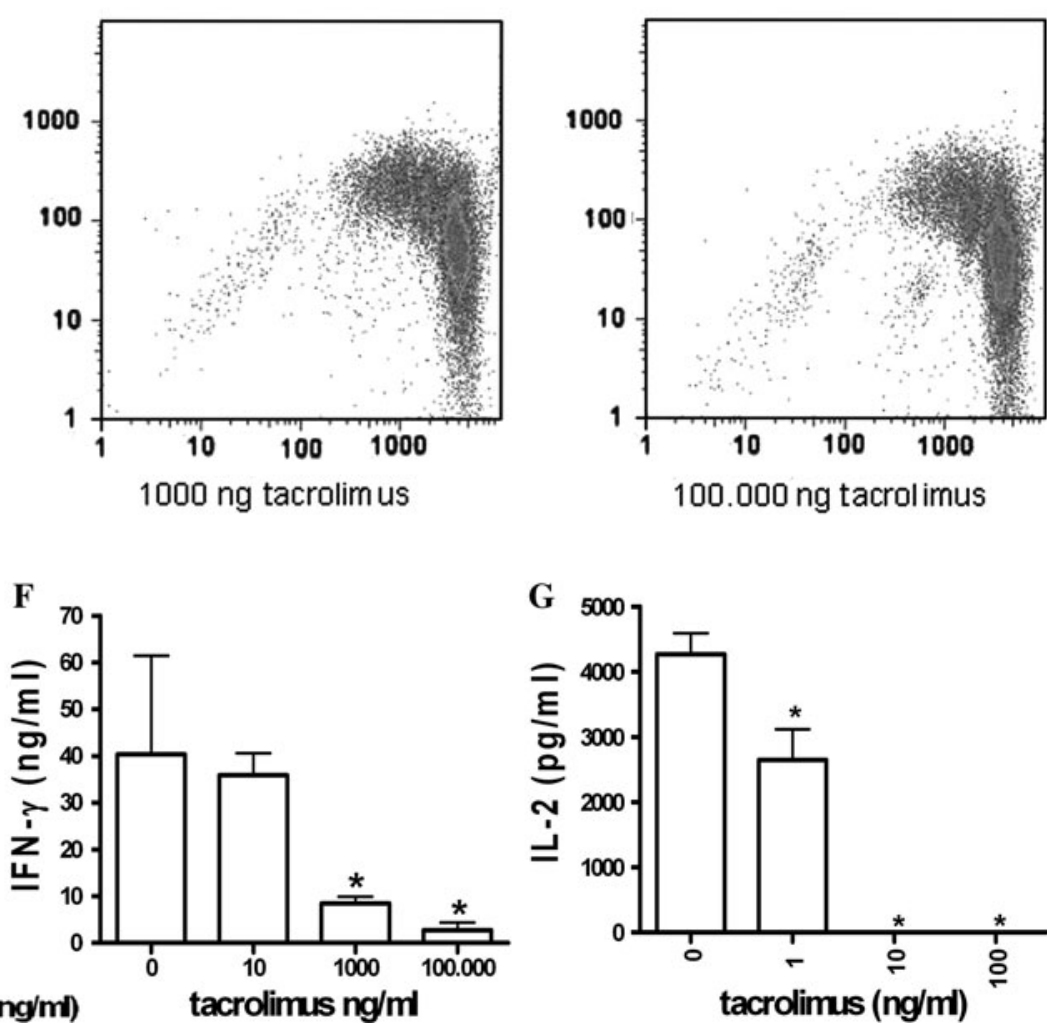
In Vivo Studies: Mice

All animal procedures and protocols were performed with the approval of the local institutional animal studies ethics committee. All mice were purchased from Charles-River. At least four animals per treatment group were used.

\section{Tacrolimus Enema Treatment of Naïve Mice}

The first experiment was to compare colonic and blood levels of tacrolimus upon oral or intra-rectal tacrolimus treatment. Eight- to ten-week-old BALB/C mice were anaesthetized with isoflurane-gas and $150 \mu \mathrm{l}$ of tacrolimus $0.1 \mathrm{mg} / \mathrm{ml}$ was installed either locally in the colon by means of a catheter or intra-gastrically by means of a orogastric gavage. The mice were killed $18 \mathrm{~h}$ after drug administration. Blood was collected in EDTA $(1.5 \mathrm{mg} / \mathrm{ml})$ and the colon was divided into a proximal part and a distal part. Tissue was homogenized in a buffer containing $20 \mathrm{mM}$ Tris (pH 7.4), $10 \mu \mathrm{g} / \mathrm{ml}$ leupeptin (Sigma-Aldrich), $200 \mathrm{mU} / \mathrm{ml}$ aprotinin (Sigma-Aldrich), and $20 \mu \mathrm{g} / \mathrm{ml}$ phenyl methyl sulphonyl fluoride [14] using a Polytron homogenizer (PT1200, Kinematica AG, Switzerland). Protein levels were then determined in colonic homogenates using the Pierce Bicinchoninic acid assay (BCA, Interchim). Subsequently, tacrolimus levels were determined in $1 \mathrm{mg}$ colonic protein and in blood using a tacrolimus ELISA (PRO-Trac II, Diasorin).

A second experiment was setup to determine whether immune suppression was achieved at $18 \mathrm{~h}$ of local administration of tacrolimus. Eight- to ten-week-old $\mathrm{BALB} / \mathrm{C}$ mice were anaesthetized by isoflurane-gas and $150 \mu \mathrm{l}$ of tacrolimus 0 or $1 \mathrm{mg} / \mathrm{ml}$ was installed in the colon. The mice were killed after $18 \mathrm{~h}$ and lamina propria lymphocytes-(LPL), iliac lymph node-(ILN), mesenteric lymph node-(MLN) and spleen-lymphocytes were isolated and subsequently cultured and stimulated with $2 \mu \mathrm{g} / \mathrm{ml} \alpha \mathrm{CD} 3$ and $2 \mu \mathrm{g} / \mathrm{ml} \alpha \mathrm{CD} 28$ antibodies as described previously [10]. After $72 \mathrm{~h}$, the supernatant was collected and IL-2 concentration was measured by means of ELISA.

\section{Results}

Tacrolimus Inhibits Activity of Local T Cells and Antigen-Presenting Cells but Leaves Epithelial Cells Unaffected In Vitro

To study whether tacrolimus is able to directly affect cells that are present in the colonic mucosa, the immunomodulatory effects were studied in vitro on several cell lines and ex vivo isolated cells.
First, the immunomodulatory effect of tacrolimus on colonic epithelial cells was evaluated. Caco-2 cells that were pretreated with tacrolimus before stimulation with peptidoglycan did not show an inhibition of their capacity to produce the chemokine IL-8 (Fig. 1a). Importantly, tacrolimus did not cause an increase of epithelial cell death at any of the used tacrolimus concentrations (data not shown).

Second, the effect of tacrolimus on local subsets of $\mathrm{T}$ cells was evaluated. First, we aimed to determine whether local lymphocytes were susceptible to immunomodulatory effects of tacrolimus in vitro. LPLs isolated from murine colon and stimulated with $\alpha \mathrm{CD} 3$ and $\alpha \mathrm{CD} 28$ antibodies ex vivo in the presence of tacrolimus display a total blockade of their IL-2 production at a dose of $10 \mathrm{ng} / \mathrm{ml}$ tacrolimus (Fig. 1b). The activation of an NKT cell line stimulated by a phorbol ester was inhibited by tacrolimus in a dose-dependent manner (Fig. 1c).

Third, the effect of tacrolimus on antigen presentation was evaluated as this process is crucially implicated in colonic inflammation. Thereto, DCs were loaded with the protein antigen OVA in the presence or absence of tacrolimus prior to consecutive incubation with $\mathrm{T}$ cells that have an OVA-specific $\mathrm{T}$ cell receptor (DO11-10 $\mathrm{T}$ cells). DCs treated with tacrolimus were less able to stimulate $\mathrm{T}$ cells to proliferate and produce IFN- $\gamma$. After $72 \mathrm{~h}$ of coincubation with tacrolimus, pre-treated DCs T cells showed a dose-dependent increase in the percentage of undivided cells (Fig. 1d, e) and a dose-dependent decrease of their IFN- $\gamma$ production (Fig. 1f). This inhibitory effect of tacrolimus on antigen presentation did not seem to be restricted to classical protein antigen presentation since the same results were obtained when this experiment was performed in a system that is independent of classical MHC (-II) presentation but dependent of a lipid non-classical Cd1d-restricted pathway (Fig. 1g).

\section{Colonic Application of Tacrolimus Results in Local Retention and Local Immune Suppression}

We compared colonic and systemic tacrolimus levels after oral administration, which is the common route for systemic therapy, and after intra-rectal administration. As demonstrated by Fig. 2a, blood levels of intra-rectal treated mice are similar to blood levels of orally treated mice after $18 \mathrm{~h}$ of treatment. Importantly, upon rectal administration, a 14-fold higher concentration of tacrolimus was reached within colonic tissue in comparison to oral administration (Fig. 2a).

To study immunomodulatory effects after local treatment with tacrolimus ILN-, LPL-, MLN- and spleen lymphocytes were isolated from rectal tacrolimus-treated mice after $18 \mathrm{~h}$. These cells were stimulated polyclonally ex vivo with $\alpha \mathrm{CD} 3$ and $\alpha \mathrm{CD} 28$ antibodies. After $48 \mathrm{~h}$ of stimulation, IL-2 concentration was measured in the 
supernatant. Lymphocytes derived from colon draining ILNs of tacrolimus-treated mice show a significant inhibition of IL-2 production compared to lymphocytes of the saline-treated mice. Lymphocytes derived from the lamina propria of mice treated with tacrolimus also displayed less IL-2 production than lamina propria $T$ cells from mice treated with saline only, albeit not significantly. Local tacrolimus treatment did not affect the IL-2 production of spleen or MLN-derived lymphocytes (Fig. 2b).

\section{Discussion}

In these studies we sought substantiation of tacrolimus as a local therapeutic in IBD patients. First we established that tacrolimus elicits a potent immunosuppressive effect on several mucosal immune cells that are crucially implicated in the pathogenesis of IBD. As such, our in vitro experiments show that IL-2 production of both lamina propria $\mathrm{T}$ cells as well as an NKT cell line was strongly inhibited by tacrolimus in a dose-dependent fashion. Notably, recent work has implicated that NKT cells play an important role in the IBD pathogenesis and these cells may therefore serve as a new target for immunomodulatory therapy in IBD. The suppression of IL-2 is a well-known feature of calcineurin inhibitors. Also, systemic tacrolimus administration has been linked to mucosal immune suppression in previous work [15], however, the direct effect on the normally resilient mucosal $\mathrm{T}$ cells and NKT cells had not been studied earlier.

Interestingly, we observed that the activation of $\mathrm{T}$ cells or NKT cells could also be inhibited indirectly by targeting antigen-presenting cells with tacrolimus. Both MHC class

Fig. 2 Colonic application of tacrolimus in mice results in mainly local presence of the drug and local immune suppression. a Mice were treated with $150 \mu \mathrm{l}$ of tacrolimus $(0.1 \mathrm{mg} / \mathrm{ml})$ either intrarectally or intragastrically. Eighteen hours later, mice were sacrificed and colons and blood were removed. Colons were divided into a proximal part and a distal part, and homogenized. Tacrolimus levels were measured in blood and the homogenates by means of ELISA. The first four bars reflect the concentration of tacrolimus present in the colon (ng per mg protein). The last two bars represent the concentration of tacrolimus present in the blood ( $\mathrm{ng}$ per $\mathrm{ml}$ ). Irrespective of the route of administration, at $18 \mathrm{~h}$ after tacrolimus treatment, comparable amounts of tacrolimus are detectable in the blood. Tacrolimus was present in the colon in higher amounts after rectal than after oral administration of the drug. b Mice were treated with $150 \mu \mathrm{l}$ of tacrolimus $(1 \mathrm{mg} / \mathrm{ml})$ or saline intrarectally. At $18 \mathrm{~h}$ after treatment, lymphocytes were isolated from lamina propria, iliac lymph node, mesenteric lymph node, and spleen, and stimulated for $72 \mathrm{~h}$ with $\alpha \mathrm{CD} 3 \alpha \mathrm{CD} 28$ antibodies. IL-2 production was measured in the supernatant by means of ELISA. Bars represent the average IL-2 production of at least four mice. Lamina propria-derived lymphocytes (LPL) and colon draining lymph node-derived lymphocytes (ILN) of tacrolimus-treated mice tend to produce less IL-2 upon polyclonal stimulation than lymphocytes derived from saline-treated mice, whereas no differences in IL-2 production were observed within systemically derived lymphocytes. Asterisks indicate statistical significance $(P<0.05)$. Error bars indicate the standard error of the mean
II restricted and non-restricted antigen presentation was strongly inhibited by tacrolimus. It has been suggested earlier that tacrolimus inhibits the $\mathrm{T}$ cell stimulatory capacity of DCs [16-18]. Here we show that this concept can be extended to non-classical ways of lipid antigen presentation. The mechanism behind these observations has yet to be clarified but may also involve calcineurindependent processes. Calcineurin inhibitors specifically affect lymphocytes as their activation critically depends on a restricted amount of the phosphatase. At higher (local) concentrations of tacrolimus the activity of the drug may be less restricted to lymphocytes and also affect cells that are less dependent on calcineurin [19, 20]. Importantly, we did not observe any suppressive effects of tacrolimus on the responsiveness of epithelial cells to bacterial peptidoglycan. The latter suggests that one of the hallmarks of mucosal homeostasis that is microbial sensing by the epithelium will remain intact during tacrolimus treatment.
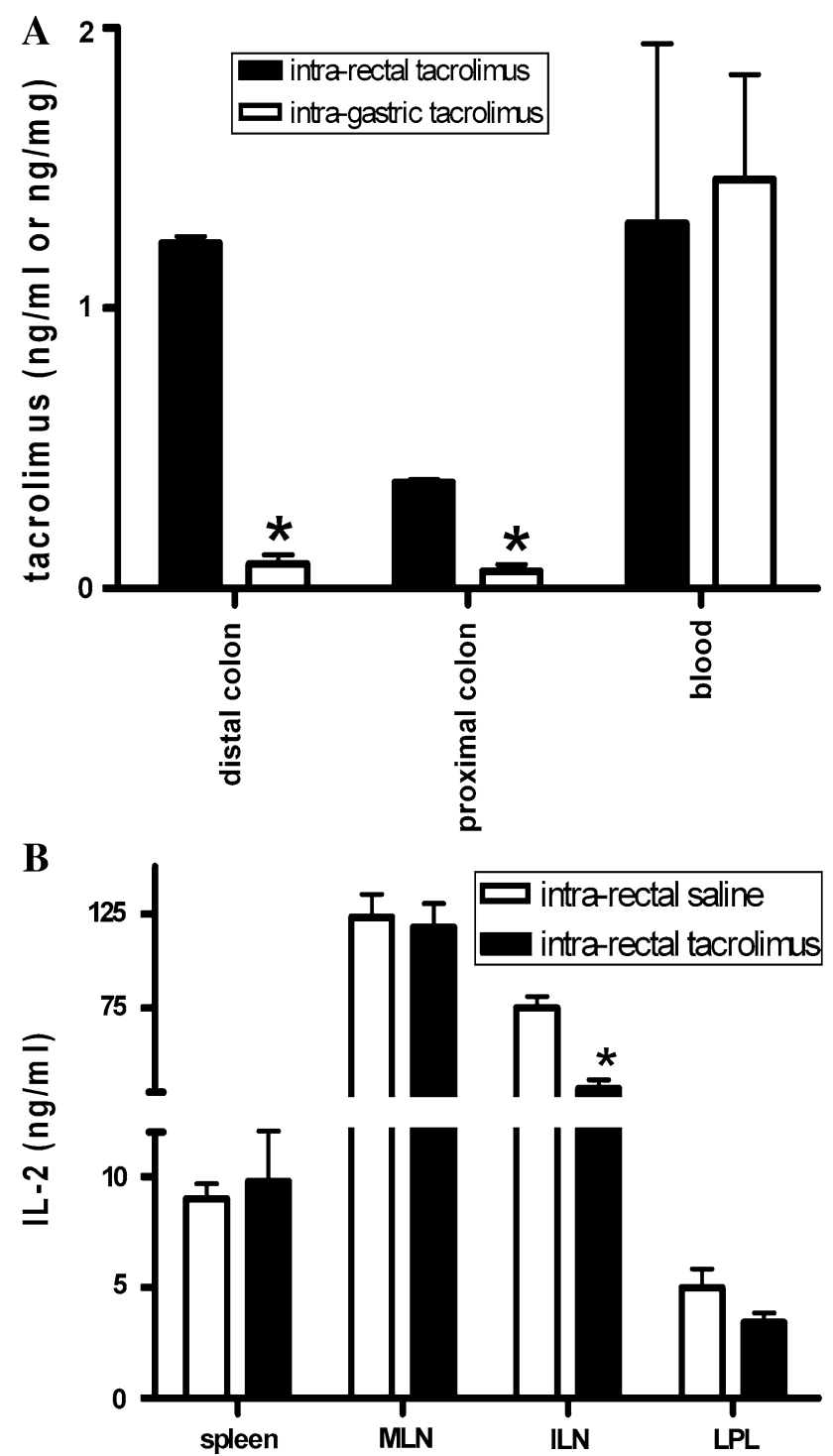
A next step in our studies was to prove that locally applied tacrolimus is retained in the mucosa and elicits its immune suppression only at the local site of application. We found that rectal application of tacrolimus yielded much higher mucosal levels of this drug compared to oral treatment whereas systemic levels were quite similar with both administration routes. This implicates that much lower doses of tacrolimus are required to obtain a therapeutic level in the colon after local application than after systemic application, which limits systemic tacrolimus levels. This experiment illustrates that there is a difference in mucosal levels, depending on the route of administration. As there are pharmacokinetic differences between mice and humans, we decided not to extend in this current protocol. For further insight into (mucosal) tacrolimus pharmacokinetics, human studies should be performed.

As anticipated, mice treated with tacrolimus rectally displayed inhibited immune responses of cells derived from the local draining lymph nodes, whereas more distal (mesenteric lymph nodes) and concurrent systemic (spleen) immune responses remained intact. These data confirm that tacrolimus is indeed retained and active in the mucosa at the local site of application. A proper dose-finding study in humans should reveal which dosage is best suited for use in patients.

These studies show that tacrolimus has potent immunesuppressive capacities when applied directly upon the mucosa. In vitro, it potently inhibits activation of lamina propria (NK)T cells and of both classical as well as nonclassical antigen presentation, while leaving epithelial microbial defense intact. In vivo application of tacrolimus in murine colons yielded an inhibited local $\mathrm{T}$ cell response ex vivo, while leaving systemic $\mathrm{T}$ cell responses intact. High colonic levels of tacrolimus were reached after rectal administration in comparison to systemic (oral) treatment in mice. This implicates that lower doses of tacrolimus may be used in local application, limiting systemic side-effects. These data provide a rationale to further study local application of tacrolimus in IBD patients.

Acknowledgments We would like to thank L. de Ruiter of the Laboratory of Pediatrics, Erasmus MC Rotterdam for laboratory support.

Open Access This article is distributed under the terms of the Creative Commons Attribution Noncommercial License which permits any noncommercial use, distribution, and reproduction in any medium, provided the original author(s) and source are credited.

\section{References}

1. van Dieren JM, Kuipers EJ, Samsom JN, Nieuwenhuis EE, van der Woude CJ. Revisiting the immunomodulators tacrolimus, methotrexate, and mycophenolate mofetil: their mechanisms of action and role in the treatment of IBD. Inflamm Bowel Dis. 2006; 12:311-327.

2. Baumgart DC, Wiedenmann B, Dignass AU. Rescue therapy with tacrolimus is effective in patients with severe and refractory inflammatory bowel disease. Aliment Pharmacol Ther. 2003;17: $1273-1281$

3. Bousvaros A, Kirschner BS, Werlin SL, et al. Oral tacrolimus treatment of severe colitis in children. J Pediatr. 2000;137: 794-799.

4. Fellermann K, Tanko Z, Herrlinger KR, et al. Response of refractory colitis to intravenous or oral tacrolimus (FK506). Inflamm Bowel Dis. 2002;8:317-324.

5. Hogenauer C, Wenzl HH, Hinterleitner TA, Petritsch W. Effect of oral tacrolimus (FK 506) on steroid-refractory moderate/severe ulcerative colitis. Aliment Pharmacol Ther. 2003;18:415-423.

6. Ogata $\mathrm{H}$, Matsui $\mathrm{T}$, Nakamura $\mathrm{M}$, et al. A randomised, dosefinding study of oral tacrolimus (FK506) therapy in refractory ulcerative colitis. Gut. 2006;55:1255-1262.

7. van Dieren JM, van Bodegraven AA, Kuipers EJ, et al. Local application of tacrolimus in distal colitis: feasible and safe. Inflamm Bowel Dis. 2009;15:193-198.

8. Lawrance IC, Copeland TS. Rectal tacrolimus in the treatment of resistant ulcerative proctitis. Aliment Pharmacol Ther. 2008;28: $1214-1220$.

9. Fuss IJ, Heller F, Boirivant M, et al. Nonclassical CD1drestricted NK T cells that produce IL-13 characterize an atypical Th2 response in ulcerative colitis. J Clin Invest. 2004;113: 1490-1497.

10. de Koning BA, van Dieren JM, Lindenbergh-Kortleve DJ, et al. Contributions of mucosal immune cells to methotrexate-induced mucositis. Int Immunol. 2006;18:941-949.

11. Samsom JN, van Berkel LA, van Helvoort JM, et al. Fc gamma RIIB regulates nasal and oral tolerance: a role for dendritic cells. J Immunol. 2005;174:5279-5287.

12. Hershberg RM, Framson PE, Cho DH, et al. Intestinal epithelial cells use two distinct pathways for HLA class II antigen processing. J Clin Invest. 1997;100:204-215.

13. Hershberg RM, Cho DH, Youakim A, et al. Highly polarized HLA class II antigen processing and presentation by human intestinal epithelial cells. J Clin Invest. 1998;102:792-803.

14. Arya R, Grossie VB Jr, Weisbrodt NW, Lai M, Mailman D, Moody F. Temporal expression of tumor necrosis factor-alpha and nitric oxide synthase 2 in rat small intestine after endotoxin. Dig Dis Sci. 2000;45:744-749.

15. Elitsur Y, Liu X, Dosescu J, Moshier JA. FK-506 and cyclosporine A (CsA) immunomodulation of the human gut mucosal immune system. Dig Dis Sci. 1995;40:1934-1940.

16. Tiefenthaler $M$, Hofer $S$, Ebner $S$, et al. In vitro treatment of dendritic cells with tacrolimus: impaired T-cell activation and IP-10 expression. Nephrol Dial Transplant. 2004;19:553560.

17. Cos J, Villalba T, Parra R, et al. FK506 in the maturation of dendritic cells. Haematologica. 2002;87:679-687.

18. Lee YR, Yang IH, Lee YH, et al. Cyclosporin A and tacrolimus, but not rapamycin, inhibit MHC-restricted antigen presentation pathways in dendritic cells. Blood. 2005;105:3951-3955.

19. Crabtree GR. Generic signals and specific outcomes: signaling through Ca2+, calcineurin, and NF-AT. Cell. 1999;96:611-614.

20. Klee CB, Ren H, Wang X. Regulation of the calmodulin-stimulated protein phosphatase, calcineurin. J Biol Chem. 1998;273: 13367-13370. 